\title{
Development of Reflexive Thinking as Important Motivational Potential for Teaching Activity
}

\author{
M.Yu. Smetanina \\ Department of Foreign Languages in Economics and Law \\ Altai State University \\ Barnaul, Russian Federation \\ E-mail: smtmarina@mail.ru
}

\author{
E.V. Abubakarova \\ Humanitarian Sciences and Cross-cultural Communications \\ Department \\ Altai branch of the Financial University under the \\ Government of the Russian Federation \\ Barnaul, Russian Federation \\ E-mail: hellen_81@mail.ru
}

\author{
N.A. Bobrovskaya \\ Department of Foreign Languages \\ Altai State Technical University named after I.I. Polzunov \\ Barnaul, Russian Federation \\ E-mail: bobrovskaja_n@mail.ru \\ O.N. Zherdeva \\ Humanitarian Sciences and Cross-cultural Communications \\ Department \\ Altai branch of the Financial University under the \\ Government of the Russian Federation \\ Barnaul, Russian Federation y \\ E-mail: vigrijanova@mail.ru
}

\author{
O.V. Kozina \\ Department of Foreign Languages \\ Altai State Pedagogical University \\ Barnaul, Russian Federation \\ E-mail: cck2004@mail.ru
}

\begin{abstract}
The article examines the process of teachers training at Qualification Improvement Centers. Modern pedagogical approaches and the methods of work with foreign language teachers are analyzed. The purpose of the study is to reveal the principles of educational process organization that contribute to professional advancement, such as integration of methodological, special and psycho-pedagogical training. Particular attention is drawn to the reflexive approach as an effective mechanism for raising the level of teaching proficiency. According to this approach, the program focused on gaining a high level of competence in the use of modern teaching methods was elaborated. It is aimed at the development of the basic components of teachers' preparedness. Special attention is paid to the description of the reflexive evaluative component. It is noted that the implementation of the developed program requires the particular organization of the teaching process connected with the permanent analysis of educational experience and selfevaluation of personal achievements. The article concludes that learner-centered and interactive methods of teaching offer better opportunities for working in the field of professional improvement and the development of reflexive thinking creates the motivational potential for pedagogical activity.
\end{abstract}

Keywords - qualification improvement, reflexive thinking, modern teaching techniques, interactive methods of teaching

\section{INTRODUCTION}

Describing the latest trends and challenges in the sphere of continuing pedagogical education it should be noted that methodological approaches to the organization of educational activities are intensively developing. It is determined by the fact that the problem of professional improvement in the sphere of higher education has become urgent because there is a demand in a labor market for specialists capable of innovative technology conceptualization, willing to selfimprovement, and self-actualization in the professional activity [1]. Besides, researchers are discussing the importance of developing research abilities, emphasizing that teachers are not able to successfully solve the urgent problems associated with the development and implementation of innovations because of insufficient research experience [2].

Due to these tendencies psychological and pedagogical approaches, technologies and teaching methods are intensively updating in accordance with the principles of reflexivity, autonomy, modular structuring of educational programs and acquire an activity-oriented and personality-oriented character.

It's admitted that lifelong learning begins during the student days and continues throughout the life [3]. Education experts also note that teachers should be capable of constant and systemic self-education pointing out that the evaluation of professional activity becomes an effective tool of performance improvement in the context of professional growth and continuing education [4].

That's why this research emphasizes the significance of the reflexive approach as a means of improving professional 


\section{RESEARCH}

Speaking about current trends in the sphere of continuing teacher education it is worth noting that methodological approaches at Re-training and Qualification Improvement Centers have distinguishing features. Russian researchers analyzing the essence of lifelong education point out that flexibility (use of various forms, means, and methods of teaching) is one of the basic features of continuing professional education today [6]. Obviously, in this area practice-oriented technologies are much more effective [7]. At the same time, the choice of teaching techniques aims at actualization of personal teaching experience and connected with self-esteem and self-diagnosis of personal achievements.

The work on improving professional pedagogical activity has allowed to develop and implement the program for optimizing language teachers training to apply new teaching methods. In the current research technologies, methods and techniques of teaching a foreign language that aim at enhancing cognitive activity are of particular interest.

It is stated (in the hypothesis of the proposed program) that the process of language teachers training is more effective if the organizational and methodological conditions are created based on andragogic approach to education. New target priorities in teaching foreign language to adult learners within principles of andragogy are being discussed by scientists today. It is noted that while learning a foreign language, an adult person acquires new relationships with the world, new personal qualities and permanent pursuit of self-improvement [8]. Therefore, the program is based on one of the main andragogic principles - the principle of reflexivity, which implies that adults' education is organized within a constant analyzing the learning process, their own actions and achievements.

It's obvious that appropriate approaches must be used for organization of teachers' cognitive activity, such as openness and obvious ambiguity in solving professional and communicative problems, analysis of personal experience in learning a foreign language, a participative approach to analyzing new knowledge and solving problems of professional activity, the reflection of their own and other people's experience in teaching a foreign language, etc. [9].

The practice shows that such an organization of the teaching process contributes to the formation of a high level of preparedness among teachers to apply new training technologies.

Next, it makes sense to analyze the structure of preparedness of teachers to apply modern teaching methods, since it is necessary for the subsequent study of the problem of teachers' training in terms of applying the reflexive approach.

In accordance with the current understanding of teachers' preparedness, the following components of pedagogical preparedness were distinguished as the most important ones: cognitive, technological, reflective-evaluative, and motivational. The given components of preparedness are sure to be efficient in professional development under the conditions of the innovative educational practice only if they are interconnected. 
However, in this research, the importance of the development of teachers' reflective abilities for their professional development is emphasized. That's why the reflective evaluative component of preparedness should be described and criteria for the formation of the investigated component must be highlighted, as well as the abilities considered as professionally significant indicators of the development of this component of preparedness (Table I) [10].

On the basis of the described criteria and abilities, it is possible to determine and characterize the development levels of language teachers' preparedness to implement methodical innovations in their work.

To encourage teachers' willingness to implement modern teaching methods, it is necessary to provide organizational and pedagogical conditions, which can be created when interactive training technologies are used and problem-based learning methods are applied (the technology of the development of critical thinking, the project methods and others).

For this purpose, interactive lectures, masterclasses, trainings, round-table conferences, discussions, role plays are held. Such tasks as brainstorming (a collective method of searching for original ideas and solutions), working environment simulation, case study (studying and discussing specific situations), insert method (completing tables with the information from given texts) contribute to the efficiency of teacher training process. Besides, a regular work with audio and video materials is provided, followed by discussion and analysis of the presented problems, as well as making presentations.

TABLE I. CRITERIA FOR FORMATION OF THE REFLECTIVE EVALUATIVE COMPONENT OF PREPAREDNESS OF LANGUAGE TEACHERS TO APPLY MODERN METHODS IN TEACHING ENGLISH

\begin{tabular}{|c|c|}
\hline $\begin{array}{c}\text { Reflection and critical self-assessment of } \\
\text { professional activity }\end{array}$ & $\begin{array}{c}\text { The need for improvement of personal capabilities } \\
\text { and abilities }\end{array}$ \\
\hline \multicolumn{2}{|c|}{ Factors } \\
\hline $\begin{array}{l}\text { - constant self-control and self-assessment of professional activity } \\
\text { - ability to analyze and evaluate personal professional activity and students } \\
\text { work } \\
\text { - ability to determine cause-and-effect relationships between organization of } \\
\text { professional activity and the results of students' work } \\
\text { - ability to draw correct conclusions based on analysis } \\
\text { - willingness to implement the selected technology for teaching a foreign } \\
\text { language and evaluate its effectiveness }\end{array}$ & $\begin{array}{l}\text { - awareness of the importance of the professional development in the sphere } \\
\text { of elaboration and implementation of modern teaching methods } \\
\text { - problematic and search character of professional activity } \\
\text { - flexibility of thinking in the field of development and implementation of } \\
\text { new methods of teaching English } \\
\text { - willingness to make changes in the organization of the teaching process } \\
\text { using innovative techniques for teaching English } \\
\text { - awareness of personal professional strengths and weaknesses }\end{array}$ \\
\hline
\end{tabular}

Another important trend in higher education nowadays is increasing use of digital technologies and an expansion of online-learning formats, which poses new challenges for university faculties to master the pedagogical competences in teaching online. It is noted that Universities tend to involve an increasing number of teachers in the design and delivery of online courses taking into account factors, incentives and barriers affecting faculty's participation in online teaching [11].

In this study digital technologies and online educational platforms are viewed as the most efficient ways for learning new language skills because MOOCs (Massive Open Online Courses) such as Coursera, FutureLearn, Stepic and many others provide exciting opportunities for learning and teaching new educational methods, that's why Internet resources are extensively used the in the process of teachers training.

Next, the detailed analysis of the most popular technologies and methods used in the training course for language teachers is presented.

The technology for the development of critical thinking is used in practical classes as it allows the educational process to be carried out based on cooperation, conciseness and is associated with evaluative reflexive thinking.

Among the specialists in the sphere of adult education, the methods of developing critical thinking became popular at the end of the 20th century, as it was recognized that adults perform work in the educational process due to their logic, comparison, active intellectual activity and reflective judgments.

Russian researchers of critical thinking (I.O. Zagashev, S.I. Zaire-Bek) have revealed that it is connected with certain qualities and skills that form the research culture of a learner and teacher at a high level [12].

A particular importance is attached to the ability to think critically in the modern information space, because according to the researchers this ability allows to acquire the necessary knowledge independently, find ways to solve arising problems, analyze and make hypotheses for solving problems, draw conclusions and think outside the box, as well as to be tolerant in various communication situations [13].

This technology is more effective if the work on foreign texts is followed by the discussion of the problems on real-life situations connected with teaching. It is important to take into consideration that the technology requires passing through several stages: calling, comprehension of the content and reflection. Experience shows that such work allows teachers to acquire information, consider problems from different points of view, and work on their solution in collaboration with each other during the training course.

As mentioned above, practical classes include applying the methods of the problem-based learning which aim at creating problematic situations at all stages of the learning process: 
while explaining, practicing, and controlling. It was possible in this study to distinguish the most effective teaching methods in the educational process with an adult audience based on comparison, analysis, generalization and comparison. At the same time, it is important to observe the basic principles of creating problem-based situations that require different points of view on the discussed problem or creating contradictions, which leads the audience to an active discussion, expressing a reasoned point of view and formulating own conclusions.

For example, course participants are asked to signify their agreement or disagreement about a contradictory statement, comment on the statement in accordance with their opinion or attitude, complete or rephrase the idea, find possible alternative views on the idea or actions, propose the ways of solving problems (with limited discussion time), make a rating (of the qualities of a teacher) in order of importance etc.

When working on texts or articles with problematic content, teachers can be asked to give an alternative title to the article, formulate the main idea and problem, express opinions, start a debate on scanned texts, and discuss the problems from various points of view. It is advisable to organize the work in small groups (of 4 or 5 people), and then suggest to answer the questions of members of other groups and judge the proposed solutions to problems.

Working on the systematization and practicing the material, it is important to use various techniques such as a "memory card" (quick, associative recording of thoughts and ideas), cinquain (summarizing information, describing feelings and ideas in a few words), cluster (highlighting semantic text units and graphic design). These techniques not only simplify remembering large amounts of information, but also require the synthesis of information, which allows to invoke reflection.

Thus, nowadays problem-based teaching is relevant with an adult audience, as it contributes to the development of productive and reflexive thinking. Besides, it is noted that analytical approach to learning results in success in educational process.

Considering the fact that teachers face a number of psychological and didactic difficulties when they learn and apply new teaching methods, it is necessary to include practical work on overcoming such difficulties in the program of the special training course. The purpose of such classes is to analyze factors that cause difficulties in giving lessons with extensive use of modern teaching technologies, as well as to find different ways of solving arising problems.

Next, the organization of the educational process is briefly described (aimed at overcoming difficulties which can emerge when teachers apply modern teaching technologies in their practical work).

These lessons are started with opening words aimed at appraising the level of methodological and psychological preparedness to overcome problems connected with discipline, different levels of language skills in groups, shortage of language and speech means, the lack of information on the topics being studied, etc. Besides, the ways of creating motivation for language learning, problems connected with the choice of individual or group activity types, planning class time, using means of speech and intonation are discussed. During the discussion, colleagues find the reasons for failures in their professional practice and share their experience in overcoming crisis situations.

Other exercises focus on the development of practical skills which are needed to overcome arising problems and difficulties. So, when discussing difficulties in applying modern teaching technologies, teachers analyze situations from real teaching practice, compare possible problems and suggest solutions, complete tables (write more options to the given solution list), describe and suggest for a discussion their own situations and give examples from their teaching practice.

It is worth pointing out that teachers should do such tasks using a foreign language in groups with subsequent discussion.

Having analyzed scientific literature on the chosen problem we learnt that E.N. Solovova studied an integratedreflexive approach and provided the description of reflection levels. This information helped us formulate tasks for the communicative block of the program. Integrated-reflexive approach involves a constant analysis of the actions and emotions of the teacher and learners, the causes of problems and difficulties, and the search for possible solutions in the existing situation followed by modeling of training situations, etc. [9].

Besides, in order to understand the gained experience better, course participants are supposed to make regular notes in "professional observation diary" and record what new things they have learnt and understood what knowledge and skills they have gained in the training course. In addition, teachers are asked to answer questions about what helped or hindered them, which tasks were easy or difficult to complete.

Therefore, the extensive use of problem solving methods and the technology of critical thinking development combined with reflective approach at all stages of training lead to the improvement of communicative, methodical and linguistic competencies of foreign language teachers.

\section{RESUlTS AND DISCUSSION}

The program implementation experience at the Qualification Improvement Centre of Altai territory and at the Altai State University showed that the effectiveness of advanced training of language teachers increases due to the developed program. The experimental results prove this.

The purpose of the experiment was to increase the level of professional preparedness of foreign language teachers to apply innovative educational methods in professional activity. Based on the assigned task, the special course "Improving the methodological and communicative competences of English teachers under new educational practice" was developed and implemented in the training course for language teachers from the Altai Region and Barnaul.

To achieve these goals, seminars and practical classes aimed at the formation of the necessary skills were organized, 
Further, in order to analyze the results of the experimental the tasks and questions for control and discussion were formulated.

Evaluation of the levels of preparedness to apply new teaching methods of teaching English was carried out through observation, testing and questionnaire at the end of the course.

One of the goals of the special course was focused on the formation of reflective skills among the course participants. In order to do this, the tasks involving all the mechanisms and levels of reflection (the process of forming reflective abilities is described in detail in the previous paragraph) were used during all the practical classes of the special course. work, a comparative analysis of the maturity levels before and after the experimental work was made. It is presented below.

In the outcome of the experiment statistical data were obtained and processed, which proved the effectiveness of the implementation of the developed program, since the initial data of the experimental and control groups coincide, and the final ones differ (Fig 1).

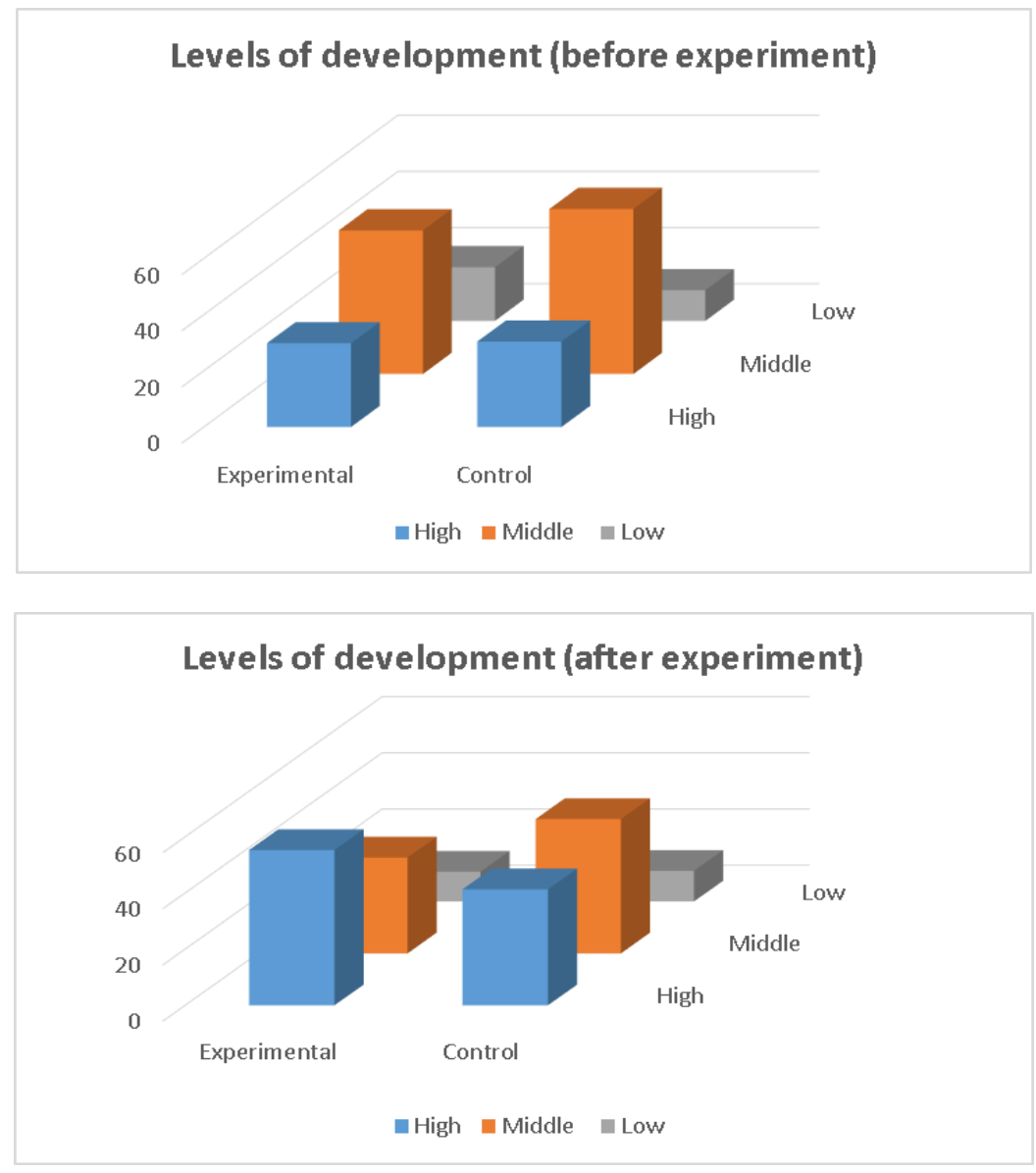

Fig. 1. Ratio of the levels of reflective-evaluative component development

The obtained data show the absence of statistically significant differences between the results in the control group at the beginning and at the end of the experiment, while the mathematical processing of the obtained data proves that at the control stage in the experimental group the level of reflectiveevaluative component development increased. Therefore, it can be concluded that the changes occurred due to the experimental teaching methods.
In the current study it is emphasized that the development of reflexive thinking is associated with the sustainable motivation for activity in the sphere of implementation of modern technologies for teaching a foreign language and the researchers who consider that there is the relationship between personal reflection and the intensity of motivation for learning have a point concerning this problem [14].

The results of the experiment (presented below) prove this statement. 
TABLE II. COMPARATIVE AHALISIS OF THE MOTIVATIONAL COMPONENT OF TEACHERS' PREPAREDNESS TO APPLY MODERN TEACHING METHODS

\begin{tabular}{|c|c|c|c|c|}
\hline \multirow{3}{*}{ Groups } & \multicolumn{3}{|c|}{ Levels of development } & \multirow[b]{2}{*}{ Total } \\
\hline & High & Middle & Low & \\
\hline & \multicolumn{3}{|c|}{ Before the experiment } & \\
\hline & $\%$ & $\%$ & $\%$ & Number of respondents \\
\hline Control & 41.3 & 47.8 & 10.9 & 46 \\
\hline \multirow[t]{2}{*}{ Experimental } & 34.0 & 44.7 & 21.3 & 47 \\
\hline & \multicolumn{3}{|c|}{ After the experiment } & \\
\hline Control & 52.2 & 36.9 & 10.9 & 46 \\
\hline Experimental & 59.6 & 29.8 & 10.6 & 47 \\
\hline
\end{tabular}

The following data on the motivational component development were obtained: more than a half of the course participants of the experimental group were actually interested in the problem of studying and introducing innovations (high level of readiness), a conscientious attitude to this kind of activity was marked. The other teachers of the experimental group showed interest in the problem and took a positive view to applying innovations in their work $(29.8 \%$ teachers are on the middle level). Consequently, the presented data indicate a significant increase in the number of teachers with strong motivation to apply innovative teaching methods (increased by 25.6\%). After the training course, the number of the respondents with the low level of preparedness decreased by $10.7 \%$ (Table II).

Some teachers from the control group also showed an increase in motivation to apply methodical innovations. At the same time, there was a slight decrease in the middle level of preparedness (by 10.9\%) upwards a higher level. The number of the respondents with the low level of preparedness remained the same. The results showed that the number of respondents from the control group who showed a true interest in the problem is less than the number of those from the experimental group.

Thus, the results prove the effectiveness of the program implementation in the training course and confirm the research hypothesis.

\section{CONCLUSION}

VI. Therefore, the concept of lifelong learning has now become a modern trend of education development in the world because of an objective necessity for development of a person as a personality and as a professional throughout his life [15]. It is also recognized that cognitive, social and reflexive components of educational competence integrated in the continuous educational process serve as an efficient tool for successful competence development [16].

The practice work shows that the effectiveness of training language teachers increases with the implementation of the proposed program. Besides, the research materials served as the basis for the development of lectures and practical tasks with university professors. The developed guidelines have been introduced into the training course at the Altai State University.

The results of the program implementation prove that the use of reflexive approach in the teaching process gives teachers the opportunity to plan and organize activities purposefully and also makes it possible to evaluate the logic and accuracy of thinking processes. It is the presence of reflective abilities that allows to analyze permanently personal experience in studying and teaching a foreign language and to correlate this experience with independent modeling of learning situations. Eventually, this contributes to the correct choice of methods and means to achieve the goals and develops the ability to make the necessary adjustments in the educational process.

The fact that the development of reflexive thinking creates the motivational potential for teaching activity and provides teachers with the necessary skills is especially important. So foreign language teachers are encouraged to create and apply new approaches, technologies and methods in their work.

\section{References}

[1] A.S. Fetisov, E.P. Komarova, G.A. Alekseeva, S.K. Gural, "Professional Qualities Formation of Educators in the System of Professional Development Training", Language and Culture, No.45, pp. 134-141, 2019

[2] T.A. Strokova, "Students' Readiness for Research Activities". Tomsk State University Journal, No. 426, 234-237, 2018.

[3] A. Merenkov, A. Sushchenko, "How Students Develop and Meet Their Need for Additional Education", Educational Studies Moscow, No. 3, pp. 204-223, 2016.

[4] A.A. Margolis, "Teacher Performance Evaluation: A Review of Best Foreign Practices", Psychological Science and Education, Vol. 24, No. 1, pp. 5-30, 2019.

[5] O.I. Lapteva, I.N. Semenov, S.G. Kulikova, Pedagogy and Psychology: study guide, Novosibirsk: Zolotoy kolos, 2015, $438 \mathrm{p}$.

[6] D.L. Matukhin, "Significance of Further Professional Education in Continuing Vocational Education System", Journal of Siberian Federal University. Humanities \& Social Sciences, Vol. 8, pp. 106-113, 2015.

[7] E.L. Rachevskii, "The key point of the system of professional development is to provide the teacher with an opportunity for self- 
[13] I.G., Zhogova, E.V. Kuzina, "Developing critical thinking skills in the professional education of higher school students", Language and Culture, No. 38. pp. 227-239, 2017.

identification at work", Psychological science and education, Vol. 22. No. 4, pp. 7-9, 2017.

[8] M.A. Ariyan, T.E.Vadeeva, "Adult learners' personal development by means of foreign language teaching: aims and ways of implementation", Language and Culture, No. 46, pp. 184-202, 2019.

[9] E.N. Solovova, Workshop on basic methodical course for teaching English language, Moscow: Prosveshchenie, 2006, 191 p.

[10] M.Yu. Smetanina, Formation of professional preparedness of foreign language teachers for using innovative educational technologies at Qualification Improvement Centres: monograph. Barnaul: Altai State University, 2014, $130 \mathrm{p}$.

[11] M.F. Galikhanov, G.F. Khasanova, "Faculty Training for Online Teaching: Roles, Competences, Contents", Higher Education in Russia, Vol. 28, No. 2, pp. 51-62, 2019 .

[12] I.O. Zagashev, S.I. Zair-bek, Critical thinking: the technology of development. Saint-Petersburg: Alyans-Delta, 2003, 284 p.
[14] T.S. Tikhomirova, N.V. Kochetkov, "Relationship between Learning Motivation and Reflection in Undergraduate Students", Psychological Science and Education, Vol. 23, No. 6, pp. 97-106, 2018.

[15] O.M. Zubkova, E.G., Ivanova, E.Y. Nadezhdina, E A. Shaturnaya, "Practical Approach to the Concept of Lifelong Learning in Linguistic Professional Education (on the Example of Special Field "State and Municipal Governance", Journal of Siberian Federal University. Humanities \& Social Sciences, Vol. 8, No. 11, pp. 2398-2407, 2015.

[16] N.A. Rybakina, "Educational competence: The essence and pedagogical model of formation in the context of lifelong education", The Education and Science Journal, Vol. 20, No. 5, pp. 32-55, 2018. 